\title{
Liver transplantation for colorectal metastasis: a stepwise approach
}

\author{
Axel Andres, Christian Toso \\ Abdominal Surgery and Transplantation, Geneva University Hospital, Geneva, Switzerland \\ Correspondence to: Axel Andres, MD. Attending Surgeon, Abdominal surgery and Transplantation, Geneva University Hospital, 4 Rue Gabrielle- \\ Perret-Gentil, 1211 Geneva, Switzerland. Email: axel.andres@hcuge.ch. \\ Provenance and Peer Review: This article was commissioned by the editorial office, Hepatobiliary Surgery and Nutrition. The article did not undergo \\ external peer review. \\ Comment on: Dueland S, Syversveen T, Solheim JM, et al. Survival Following Liver Transplantation for Patients With Nonresectable Liver-only \\ Colorectal Metastases. Ann Surg 2020;271:212-8.
}

Submitted Oct 08, 2019. Accepted for publication Oct 26, 2019.

doi: 10.21037/hbsn.2019.10.20

View this article at: http://dx.doi.org/10.21037/hbsn.2019.10.20

Six years after publishing their first results on liver transplantation for colorectal liver metastases (SECA-I) (1), Dueland et al. present a new trial on the same topic gathering 15 transplanted patients (SECA-II). They now use more restricted selection criteria, including at least 1 year between cancer diagnosis and transplantation, a documented partial $(>10 \%)$ response to chemotherapy, and the absence of extra-hepatic metastasis. After a 36-month median follow-up, they demonstrate an $83 \% 5$-year overall survival, and a $35 \% 3$-year disease-free survival. This data represents another achievement by this expert team, but four main questions remain:

(I) Is liver transplantation better than the alternative therapies at the individual level?

(II) Does the expected survival justify the use of the limited number of liver grafts at the population level?

(III) What are the ideal candidate selection criteria?

(IV) Are the results reproducible?

One should have clear answers to all four questions prior to set liver transplantation as the standard of care for selected patients with colorectal liver metastasis.

\section{Is liver transplantation better than the alternative therapies at the individual level?}

In the present SECA-II trial, 5-year overall survival was $83 \%$, which is better than the outcomes reported in the SECA-I study (60\% at 5 years), all remaining superior to palliative chemotherapy (2). One can assume that this improvement is linked to the use of more stringent patient selection criteria. However, the only way to validate this point is through the currently recruiting randomized trials comparing transplantation to chemotherapy (Transmet study, NCT02597348; SECA-III study; NCT03494946; and COLT study, NCT03803436). One could argue that the most frequent indication to oncological transplantation, namely hepatocellular carcinoma (HCC), has never been randomized to best medical care, and will probably never be so for ethical reasons. However, the present study still shows, despite refined patient selection criteria, a high recurrence rate ( $75 \%$ at 3 years), making a randomized validation mandatory.

This rate of recurrence (together with the $100 \%$ recurrence at 2 years in the SECA-I trial) represents the main limiting factor to the expansion of transplantation for colorectal metastasis (3). However, the study confirms that the lungs are the primary site of recurrence (6/15 patients), and that most of these lesions are accessible to resection. Although a longer follow-up is necessary to determine the fate of the recurring patients, many had "no evidence of disease" (NED) at last follow-up.

\section{Does the expected survival justify the use of the limited number of liver grafts at the population level?}

There is no universal consensus on the acceptable minimum 
survival after liver transplantation. However, many argue that survival after transplantation for HCC should be $>70 \%$ at 4 years (4). Applying this rule to the setting of colorectal liver metastasis is more complex. If overall survival is the goal, $>80 \%$ of the patients were alive at 5 years, validating liver transplantation for colorectal metastasis. If diseasefree survival (DFS) is the goal, transplantation could still be valid, but only for patients with good risk profile defined by Oslo score $<1$ (maximal tumor diameter $>5.5 \mathrm{~cm}$, pretransplant CEA $>80 \mathrm{mg} / \mathrm{L}$, progression on chemotherapy, time interval between diagnosis to transplant $<2$ years) and Fong score $\leq 2$ (positive nodes in the primary, disease-free interval $<12$ months, $>1$ metastasis, pre-operative CEA level $>200 \mathrm{ng} / \mathrm{mL}$, diameter of the largest metastasis $>5 \mathrm{~cm}$ ) (DFS above $70 \%$ at 4 years).

Given the lack of precise international consensus on the expected survival after liver transplantation, transplant programs still have to decide individually what type of patient with colorectal metastasis they accept to transplant, also taking graft availability into account (living-donor transplantation, areas with more donors).

\section{What are the ideal candidate selection criteria?}

The SECA-I and SECA-II studies have established that only highly selected patients with "good tumor biology" should undergo transplantation. These patients should have a long interval between diagnosis and transplantation, no progression on chemotherapy, and relatively low CEA levels and tumor size. Combining these parameters, ideal transplant candidates should have an Oslo score $\leq 1$ or a Fong score $\leq 2$ (5). In addition, the tumor FDG uptake on PET-scan could also be used to predict outcome as it reflects tumor biology (6).

Of note, transplant candidates are and will remain an extremely small subset of patients with colorectal metastasis. This point is highlighted by the present study where 15 patients have been included over 5 years from a population of 5 million people. Only 6 presented the strict Oslo/Fong profiles.

\section{Are the results reproducible?}

The team in Oslo includes multidisciplinary partners with expertise in major abdominal surgery, vascular surgery, transplantation, and in the management of cancer patients.
This point is illustrated by their proposed RAPID concept, where segments 1 to 3 are resected, a segment 2/3 allograft transplanted, before modulating the portal flow to the remaining liver, and ultimately removing the whole native liver (7). Also, the present study reports no mortality, and a relatively limited morbidity (1 liver vein thrombosis and 1 bile leak). While most patients with colorectal liver metastasis demonstrate a preserved liver function, some undergo transplantation after one or multiple liver resection (4/15 patients), which makes the procedure more challenging. It therefore remains to be determined if the presented outcomes can be reproduced elsewhere, especially if more patients with a history of one or more liver resections are considered.

Overall, the SECA-II trail confirms that transplantation is a potential treatment option for patients with nonresectable colorectal liver metastasis. The next step will need to demonstrate the superiority of transplantation compared to chemotherapy in the highly selected population of interest using a randomized design.

\section{Acknowledgments}

Funding: None.

\section{Footnote}

Conflicts of Interest: Both authors have completed the ICMJE uniform disclosure form (available at https://hbsn. amegroups.com/article/view/10.21037/hbsn.2019.10.20/coif). The authors have no conflicts of interest to declare.

Ethical Statement: The authors are accountable for all aspects of the work in ensuring that questions related to the accuracy or integrity of any part of the work are appropriately investigated and resolved.

Open Access Statement: This is an Open Access article distributed in accordance with the Creative Commons Attribution-NonCommercial-NoDerivs 4.0 International License (CC BY-NC-ND 4.0), which permits the noncommercial replication and distribution of the article with the strict proviso that no changes or edits are made and the original work is properly cited (including links to both the formal publication through the relevant DOI and the license). See: https://creativecommons.org/licenses/by-nc-nd/4.0/. 


\section{References}

1. Hagness M, Foss A, Line PD, et al. Liver transplantation for nonresectable liver metastases from colorectal cancer. Ann Surg 2013;257:800-6.

2. Dueland S, Guren TK, Hagness M, et al. Chemotherapy or liver transplantation for nonresectable liver metastases from colorectal cancer? Ann Surg 2015;261:956-60.

3. Toso C, Pinto Marques H, Andres A, et al. Liver transplantation for colorectal liver metastasis: Survival without recurrence can be achieved. Liver Transpl 2017;23:1073-6.

4. Mazzaferro V, Regalia E, Doci R, et al. Liver transplantation for the treatment of small hepatocellular

Cite this article as: Andres A, Toso C. Liver transplantation for colorectal metastasis: a stepwise approach. HepatoBiliary Surg Nutr 2020;9(3):336-338. doi: 10.21037/hbsn.2019.10.20 carcinomas in patients with cirrhosis. N Engl J Med 1996;334:693-9.

5. Fong Y, Fortner J, Sun RL, et al. Clinical score for predicting recurrence after hepatic resection for metastatic colorectal cancer: analysis of 1001 consecutive cases. Ann Surg 1999;230:309-18.

6. Grut H, Dueland S, Line PD, et al. The prognostic value of (18)F-FDG PET/CT prior to liver transplantation for nonresectable colorectal liver metastases. Eur J Nucl Med Mol Imaging 2018;45:218-25.

7. Line PD, Hagness M, Berstad AE, et al. A Novel Concept for Partial Liver Transplantation in Nonresectable Colorectal Liver Metastases: The RAPID Concept. Ann Surg 2015;262:e5-9. 